\title{
The Design of the General Concentrator
}

\author{
Lige $\mathrm{He}^{1, \mathrm{a}}$, $\mathrm{Na} \mathrm{Li}$ 2, b, Yulin Qi 2, c and Junxiao Yang 2, d \\ ${ }^{1}$ State Grid Hebei Electric Power Company, Zhuozhou Power Supply Company, Zhuozhou 072750, \\ China; \\ ${ }^{2}$ School of Electrical and Electronic Engineering, North China Electric Power University, Baoding
071003, China. \\ azzsjk@sina.com, blina18730261582@163.com, 'qiyulin589@163.com, d1348509718@qq.com
}

Keywords: distribution network, fault location, concentrator, GPRS.

\begin{abstract}
In the single-phase grounding fault location system for distribution network based on the phase method, the concentrator bears the main task of the centralized transmission data, and it is an important part of online fault location system. This paper designed a general concentrator. The concentrator cannot be only accurate upload fault information to the remote management center through GPRS module and wireless module, but also can give orders to the line terminal sensors. It also increased the GPS module, which can accurately obtain the local time, latitude and longitude location information. By the synergy of hardware and software, it implements the information interaction between concentrator and line terminal sensor, concentrator and remote management center. Through testing, the concentrator meets the requirements of real-time and reliability. The concentrator can be used for street light management system and electric power meter reading system, which has a broad application prospect.
\end{abstract}

\section{Introduction}

In power system, the probability of medium voltage distribution network fault is more than the high voltage transmission network [1]. According to statistics, in the small current grounding system, more than $80 \%$ of the distribution network is single-phase ground fault, which occupies most of the power distribution network fault [2,3].So troubleshooting timely, fast and exact positioning of single-phase earth fault are very important to the power supply reliability and the operation of power grid safety and constable.

The concentrator is designed in this paper under the background of the single-phase grounding fault location system for distribution network based on the phase method[4], and it is applied to distribution network fault location system, through the GPRS module and wireless communication module, which implements the forwarding of fault information and realizes the information interaction between the line terminal sensor and management center, so that management center can timely access to fault information and process and solve the problem of single-phase grounding fault for distribution network. The concentrator meets the requirements of real-time and reliability in single-phase grounding fault location system for distribution network based on the phase method, which has a broad development prospect.

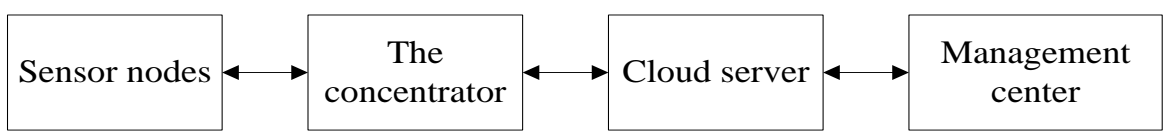

Fig. 1 Concentrator's relationship with distribution network fault location system

Concentrator's relationship with power single-phase fault location system is shown in figure 1 . The process of downward communication is that the remote management center sends instruction information to the concentrator by the cloud server, and the concentrator forwards the instruction to the line terminal sensor; Information from the line terminal sensors to the concentrator, the concentrator by the cloud server forwarding to the remote management center for upward communication. The main task of the concentrator is as follows: receiving management center's instructions, and parsing the 
command, receiving line terminal sensor information and uploaded to the management center, management center can control system running status in time to deal with fault.

\section{The hardware design of the concentrator}

The structure of concentrator is as shown in figure 2, and the hardware design mainly includes the microprocessor unit, GPRS module, wireless communication module, GPS module, and liquid crystal display units. It can guarantee the transmission of the data accurate and reliable with these units.

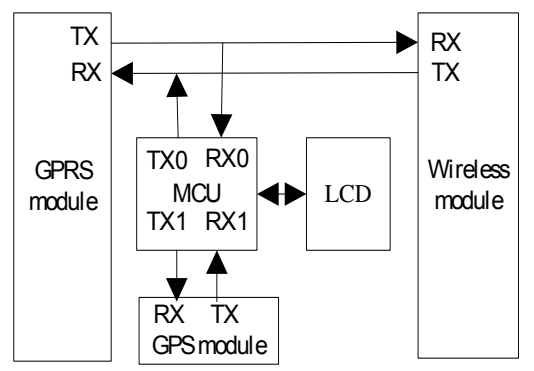

Fig. 2 The hardware design of concentrator

\subsection{The selection of the microprocessor}

The microprocessor adopts the c8051f340 produced in Silicon Labs, which is a fully integrated mixed signal on systemic MCU chip [5,6], with two serial ports of communication. It can satisfy the communication requirements of this design, realizing the communication with the GPS module and GPRS module.

\subsection{The GPRS module}

The GPRS module uses pin structure of KS-97 module [7].KS-97 module provides GPRS function. It can be configured to KS -97 by using a special configuration software and the configuration of the circuit board. The module can receive data automatically to forward, not to deal with its. On the one hand, the KS-97 is connected to the microcontroller via a serial port, management center issued the instruction information through the KS-97 to single chip microcomputer, single chip processing and reply feedback; On the other hand it will forward messages coming from a wireless module to the management center, and the management center judgment and processing the fault information.

\subsection{The wireless communication module}

Wireless communication module adopts BM100N [8]. The module is a kind of wireless ad-hoc network module. The BM100N module connected with GPRS module by a serial port and it can accept the instruction information from management center, and communicate with the line terminal BM100N module in a sensor node to convey information to the line terminal. At the same time, it would transfer the current phase information to the GPRS module, finally reach the management center.

\subsection{The GPS module}

The GPS module uses the HOLUX M-87 module. It has exquisite appearance, can accurate positioning. It has a full duplex serial TTL interface, connected with single-chip microcomputer serial port and single-chip microcomputer receives the data from the serial port and put it in the cache, the data through the program decomposition, single chip processing, to obtain useful information, and displays it on the LCD screen. 


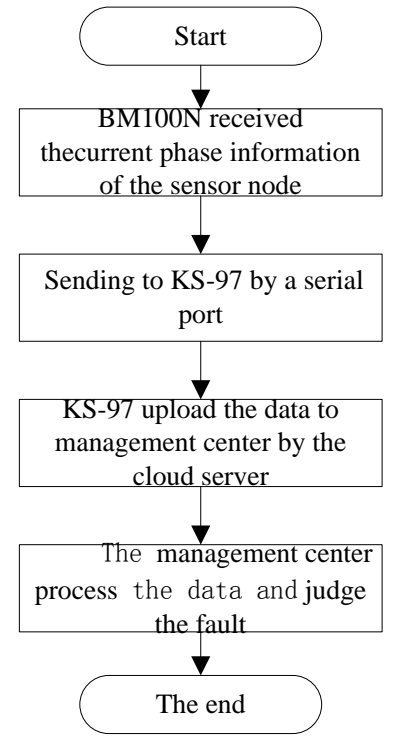

Fig. 3 The process of upward communication

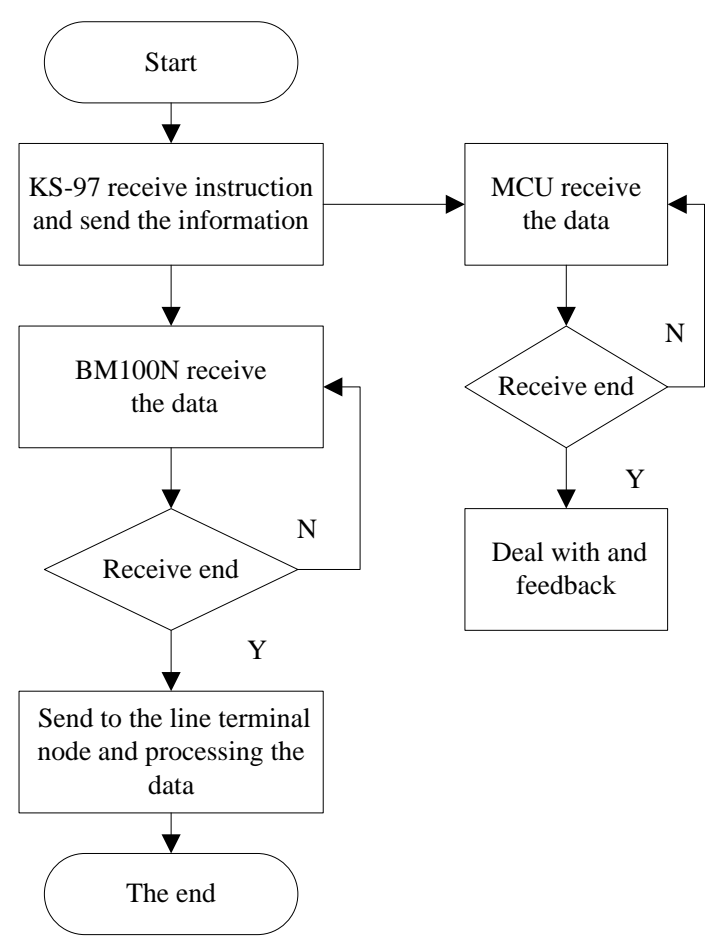

Fig. 4 The process of downward communication

\section{The software design of the concentrator}

The software design of the concentrator mainly refers to the data acquisition and transmission, including the process of upward communication, the process of downward communication as well as the process of GPS Information collection.

\subsection{The process of upward communication}

Upward communication process refers to line terminal sensors sending data to the remote management center via concentrator, the process of the communication process as showed in figure 3 . The data received from $\mathrm{BM} 100 \mathrm{~N}$ are the data from the line terminal sensor nodes. In the process of receiving, BM100N module sends the data to GPRS module via a serial port. GPRS module through the cloud server to forward the data to the management center. The management center processes the data and judges the fault.

\subsection{The process of downward communication}

Downward communication process refers to the management center to convey instructions information by the concentrator to line terminal sensor nodes. Communication flow chart as showed in figure 4. KS-97 receives information instruction by the cloud server and sent it to BM100N. After receiving information, $\mathrm{BM} 100 \mathrm{~N}$ sends the information to the line terminal sensor nodes, and single chip microcomputer can receive the instruction information from KS-97, microcontroller will reply and feedback the KS-97.

\subsection{GPS data acquisitions}

The GPS module is mainly to collect the latitude and longitude of concentrator, time date information, via a serial port connected to the MCU, MCU will store the data and processing the information to display on the LCD screen, which can obtain real-time positioning information of concentrator.

\section{Summary}

This paper designed a concentrator applied to the single-phase distribution network fault location system. It is able to accurately obtain the line terminal current phase information and can upload to the management center in time. Through the testing of a company in the northeast of China, the test results 
show that the concentrator can be accurate and reliable to transmit data and satisfy the demands of system reliability and real-time performance.

The concentrator designed in this paper is a general concentrator, it not only can be used in the distribution network fault location system, also can be used in street lighting control system and electric power meter reading system, which has a broad development prospects.

\section{References}

[1]. Guo Qingtao, Wu Tian, et al. Survey of the methods to select fault line in neutral point ineffectively grounded power system. Power system protection and control.Vol. 38 (2010) No. 2, p. 146-152.

[2]. Zheng Guping: Method of Small Current Grounding Fault Location for Distribution Automation System (Doctor of engineering, North China Electric Power University, China, 2012). P. 29-34.

[3]. Sun Guoqiang, Wei Zhinong, Tang Lifeng, et al. Pareto evolutionary algorithm for multi-objective fault location of distribution network. Electric Power Automation Equipment. Vol. 32 (2012) No. 5, p. 57-61+73.

[4]. Xu Junmiao, Qi Yulin, et al. Research and Realization of On-line Single Phase Ground Fault Location in Distribution Network Based on GPS. Electric Power Science and Engineering. Vol. 26 (2010) No. 1, p. 23-26.

[5]. Tong Changfei. C8051F series MCU development and programming with $\mathrm{C}$ language. Beijing University of Aeronautics and Astronautics Press, 2005,12-80.

[6]. Yan Gangui, Zhou Jun, Che Xiaotao,et al. Novel automatic resonance arc suppression controller based on high speed SoC MCU. Power system automation equipment. Vol. 26 (2006) No. 9, p. 68-71.

[7]. The state of eternity technology co., LTD. Beijing. KS-97 GPRS/CDMA embedded module user manual. 2012.

[8]. Bo Mingda technology co., LTD., Beijing. BM100N micropower low-power wireless ad-hoc network module user manual. 2012. 